\title{
Intermodulation distortion in wide-band dual-mode bulk ferroelectric bandpass filters
}

DOI:

10.1109/MWSYM.2005.1516675

Link to publication record in Manchester Research Explorer

\section{Citation for published version (APA):}

Chakraborty, T., Hunter, I., Kurchania, R., Bell, A., \& Chakraborty, S. (2005). Intermodulation distortion in wideband dual-mode bulk ferroelectric bandpass filters. In IEEE MTT-S International Microwave Symposium Digest/IEEE MTT S Int Microwave Symp Dig (Vol. 2005, pp. 615-618) https://doi.org/10.1109/MWSYM.2005.1516675

Published in:

IEEE MTT-S International Microwave Symposium Digest|IEEE MTT S Int Microwave Symp Dig

\section{Citing this paper}

Please note that where the full-text provided on Manchester Research Explorer is the Author Accepted Manuscript or Proof version this may differ from the final Published version. If citing, it is advised that you check and use the publisher's definitive version.

\section{General rights}

Copyright and moral rights for the publications made accessible in the Research Explorer are retained by the authors and/or other copyright owners and it is a condition of accessing publications that users recognise and abide by the legal requirements associated with these rights.

\section{Takedown policy}

If you believe that this document breaches copyright please refer to the University of Manchester's Takedown Procedures [http://man.ac.uk/04Y6Bo] or contact uml.scholarlycommunications@manchester.ac.uk providing relevant details, so we can investigate your claim.

\section{OPEN ACCESS}




\title{
Intermodulation Distortion in Wide-Band Dual-Mode Bulk Ferroelectric Bandpass Filters
}

\author{
Tanusri Chakraborty ${ }^{1}$, Ian Hunter ${ }^{1}$, Rajnish Kurchania ${ }^{2}$, Andrew Bell $^{2}$, Subhasish Chakraborty ${ }^{3}$ \\ ${ }^{1}$ Institute of Microwaves and Photonics, ${ }^{2}$ Institute for Materials Research, University of Leeds, Leeds LS2 \\ 9JT, UK, ${ }^{3}$ Microelectronics Research Centre, University of Cambridge, CB3 OHE, UK
}

\begin{abstract}
An investigation into intermodulation (IM) distortion in bulk ferroelectric bandpass filters is presented. The main objective has been to study the effect of the response time of ferroelectric material on IM distortion. In order to investigate the response time IM measurements with wide carrier frequency spacing must be performed. Thus a novel planar dual-mode bandpass filter, with $600 \mathrm{MHz}$ bandwidth at $2 \mathrm{GHz}$, has been designed and fabricated on a bulk Barium Strontium Titanate (BST) substrate. The two tone third-order IM has been measured for a range of signal separations in order to estimate the material response time.
\end{abstract}

Index Terms - Disc resonator, dual-mode filter, ferroelectric material, intermodulation distortion, response time.

\section{INTRODUCTION}

Tuneable microwave filters are very desirable components for multi-band mobile handsets. Several classes of tuneable microwave bandpass filters have been reported. These include varactor tuned filters [1] active varactor tuneable filters [2], and MESFET varactor tuned filters [3]. A fundamental problem with varactor diodes is that they respond almost instantaneously to the applied voltage. Thus not only the dc bias voltage but also the RF signal voltage will modulate the filter response, giving rise to IM distortion.

Bulk and thin-film ferroelectric materials exhibit a variation in bulk dielectric permittivity $\left(\varepsilon_{\mathrm{r}}\right)$ with applied electric field. Thus these are potentially extremely useful materials for implementing tuneable microwave devices such as integrated filters, phase shifters etc [4]. However, there is no detailed information available in the literature on the response time of bulk materials, although some data on thin-film materials has been reported [5].

One of the most popular tuneable materials is the paraelectric phase composition of Barium Strontium Titanate $\left(\mathrm{Ba}_{1-\mathrm{x}} \mathrm{Sr}_{\mathrm{x}} \mathrm{TiO}_{3}\right)$ or $\mathrm{BST}$ with $\mathrm{x}=0.4-0.6$. The paraelectricferroelectric transition temperature (Curie temperature) and the electrical properties of BST can be tailored for various device applications by varying the concentration of strontium. For microwave integrated circuit applications the field dependent permittivity and the dielectric loss at high frequency need to be low and the permittivity should exhibit with high tuneability at room temperature. So, various compositions of pure BST as well as composites of BST with different nonferroelectric oxides have been studied by the authors [6]. However, this paper presents realisation of microwave integrated filters using these materials rather than concentrating on material research.

Initially a narrowband, bandwidth $3 \mathrm{MHz}$ at centre frequency $155 \mathrm{MHz}$, microstrip combline filter using bulk BST capacitor was constructed, to study the material tuneability and to model the material non-linearity by performing IM distortion measurements [7]. The measured in-band thirdorder intercept point resulting from signals $1 \mathrm{MHz}$ apart was $+38 \mathrm{dBm}$.

The main aim was to investigate the response time of the permittivity change due to change in applied electric field. This can be approximately evaluated by applying a range of two tone test signals with variable separation. If the IM product power levels reduce as the signal separation is increased then this can be attributed to the material response time. To perform accurate measurements the bandwidth of the filter must be at least as large as the signal separation. The combline filter approach using bulk ferroelectric capacitors is not at all suitable for wide bandwidth designs because the high permittivity of the material produces high capacitance values.

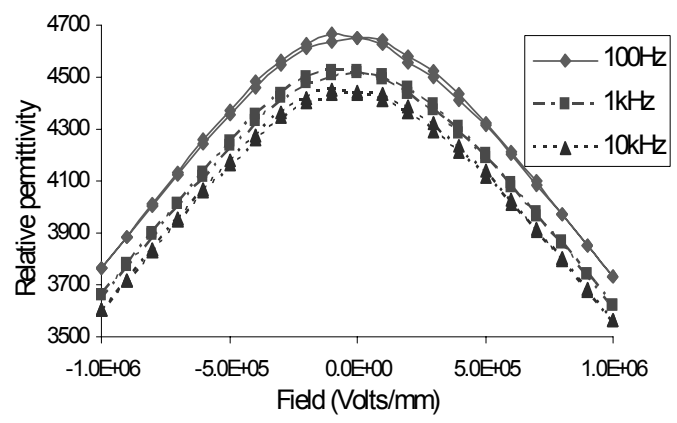

Fig. 1. Hyeteresis curves of relative permittivity as a function of dc bias for pure BST $\left(\varepsilon_{\mathrm{r}} \sim 4000\right)$.

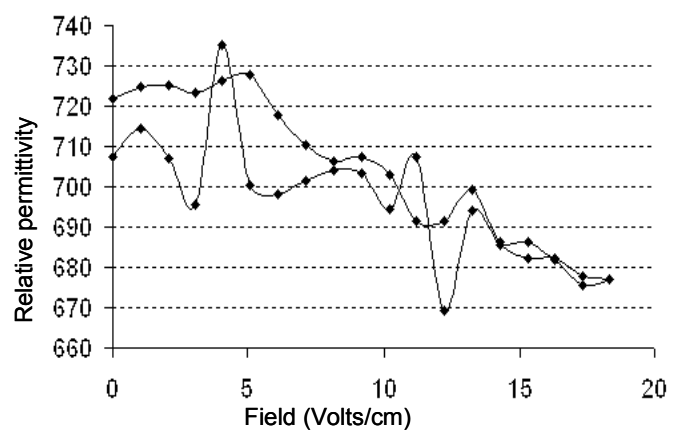

Fig. 2. Hysteresis curve of relative permittivity as a function of dc bias for $0.4 \mathrm{BST}+0.6 \mathrm{MgO}\left(\varepsilon_{\mathrm{r}} \sim 750\right)$ (courtesy Filtronic Comtek). 
Alternatively a wide-band two-pole dual-mode integrated bandpass filter with a passband bandwidth of $600 \mathrm{MHz}$ at a centre frequency of $2 \mathrm{GHz}$ on a bulk BST substrate has been designed. The measured in-band IM performance of the filter indicates that the response time of the material $\tau \leq 20 \mathrm{~ns}$.

Two different compositions of BST have been used as bulk ferroelectric substrates for microfabrication of the integrated filters; one was pure BST for $\mathrm{x}=0.4$ with $\varepsilon_{\mathrm{r}} \sim 4000$, loss tangent $\tan \delta \sim 0.0009$ and tuneability $1.38 \%$ at $50 \mathrm{kV} / \mathrm{mm}$ (Fig. 1) and the other was $0.4 \mathrm{BST}+0.6 \mathrm{Magnesium}$ Oxide $(\mathrm{MgO})$ with $\varepsilon_{\mathrm{r}} \sim 750$ at $6.7 \mathrm{GHz}, \tan \delta \sim 0.017$ and tuneability $1.02 \%$ at $10 \mathrm{kV} / \mathrm{mm}$ (Fig. 2), all are at room temperature.

\section{Microstrip COMBLine TUNEABLE BANDPASS FILTER}

A single section microstrip combline filter, shown in Fig. 3, was designed on duroid substrate. A block of BST $\left(\varepsilon_{\mathrm{r}} \sim 4000\right)$ about $2 \mathrm{~mm}$ thick, electroded with silver was used as a bulk capacitor loading the resonator line of the filter. The bulk parallel plate capacitor response as a function of dc bias voltage is shown in Fig. 4. For the purposes of simulation the CV curve was fitted with a second order polynomial.

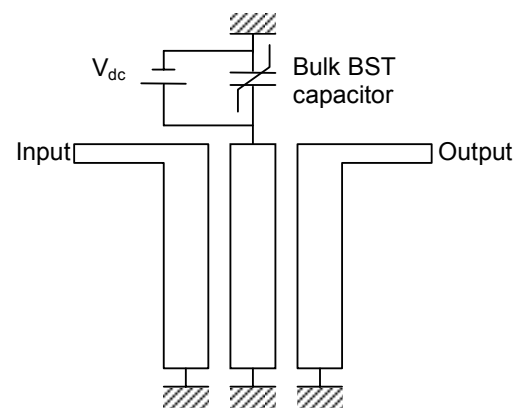

Fig. 3. Narrowband microstrip combline tuneable bandpass filter.

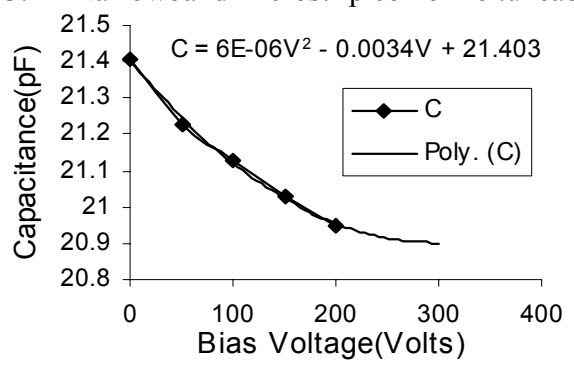

Fig. 4. Bulk BST $\left(\varepsilon_{\mathrm{r}} \sim 4000\right)$ capacitor CV curve, fitted with $2^{\text {nd }}$ order polynomial.

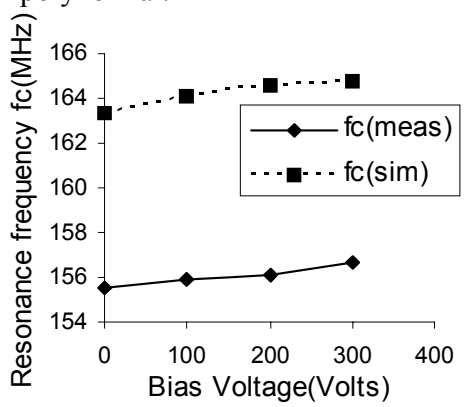

Fig. 5. Shift in resonance frequency with dc bias voltage of bulk BST $\left(\varepsilon_{\mathrm{r}} \sim 4000\right)$ capacitor loaded combline filter.
The variation of the centre frequency of the filter as a function of dc voltage is shown in Fig. 5. The small difference in resonant frequency between the measured and simulated results is due to some stray capacitance introduced in the hardware. Several hundreds of volts $/ \mathrm{mm}$ is required to achieve significant tuneability for bulk ferroelectric capacitors, so only $0.24 \%$ per 100 Volts filter tuneability has been achieved. Fig. 6 shows measured frequency response of the filter.

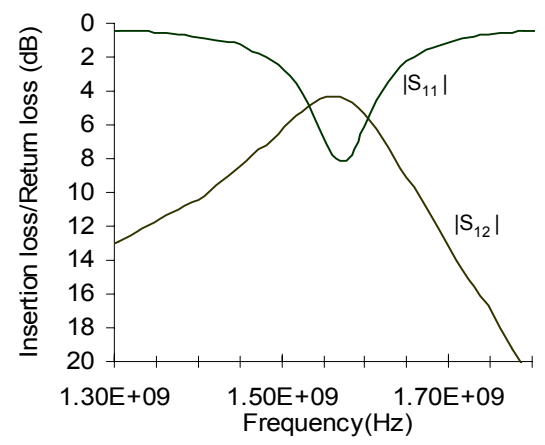

Fig. 6. Measured frequency response of combline bandpass filter at 300 Volts de bias.

\section{INTERMODULATION DISTORTION}

When multiple input signals are applied to a nonlinear circuit, IM products will appear in the output spectrum. The most significant of these are the two tone third-order products which can appear in-band. Measured and simulated results of two tone in-band third-order products in terms of third-order intercept point of the filter have been plotted in Fig. 7. Thirdorder intercept point is defined as $I P_{3}=\left(3 P_{i n}-P_{3}\right) / 2$, where $P_{i n}$ is the input signal power and $P_{3}$ is the power of the output third-order IM product. The measured $I_{3}$ was $\sim+38 \mathrm{dBm}$ for input signals separated by $1 \mathrm{MHz}$. The two tone third-order IM performance of the circuit was simulated using the harmonic balance solver in ADS (Advance Design System). This gave a check on the measurement procedure, as IM measurements are not trivial.

The $I P_{3}$ remain more or less constant with applied bias field because extremely high voltages are required to tune the bulk capacitor. Furthermore, it was not possible to evaluate the IM performance of this filter with widely separated tones as its bandwidth was only $3 \mathrm{MHz}$. The design of a wide-band filter for this purpose is described in the next section.

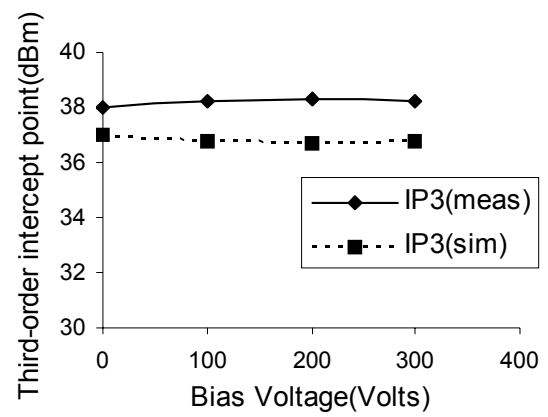

Fig. 7. Third-order intercept point with change in dc bias voltage of bulk BST capacitor loaded combline filter for fundamental signals separated by $1 \mathrm{MHz}$. 


\section{WIDE-BAND DUAL-Mode Microstrip BANDPASS FILTER - DESIGN AND FABRICATION}

A wide-band dual-mode microstrip disc resonator bandpass filter has been designed on bulk ferroelectric substrate, with $2 \mathrm{GHz}$ centre frequency and a $20 \mathrm{~dB}$ return loss with bandwidth $\sim 600 \mathrm{MHz}$. The concept of realising bandpass filter by using the two degenerate modes of a disc resonator was reported in [8]. Two orthogonal degenerate modes can be excited in the microstrip disc by taking the electrical length of the periphery equal to the guided wavelength. These two modes can be interpreted as two travelling waves: one travelling clockwise and the other anti-clockwise. By introducing some perturbation, for example, a notch along the periphery (thus introducing a path difference between the two waves) these two modes can be split or can be coupled. Increasing the coupling between these two modes widens the bandwidth of the filter.

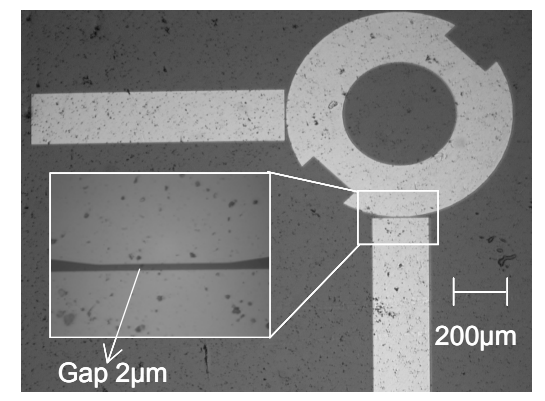

Fig. 8. Optical microscopic image of the circuit fabricated on BST ( $\left.\varepsilon_{\mathrm{r}} \sim 4000\right)$, input/output line coupling gap $2 \mu \mathrm{m}$.

The first attempt at a two-pole filter design is shown in Fig. 8 . Because of very high permittivity $\left(\varepsilon_{\mathrm{r}} \sim 4000\right)$ of the substrate material the capacitive coupling gaps of the input/output lines could not be modelled accurately using commercial electromagnetic software. An alternative direct-coupled design was employed, Fig. 9. In this case the strength of the coupling can be adjusted by feeding the input closer to the centre of a disc resonator, where the field is weaker.

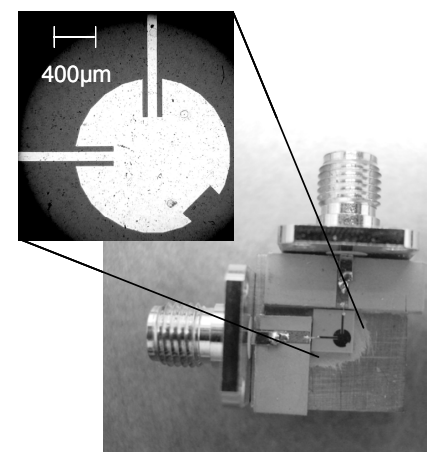

Fig. 9. Filter circuit on the test fixture, inset: enlarged microscopic image of the integrated filter on BST $\left(\varepsilon_{\mathrm{r}} \sim 750\right)$.

Microfabrication of this circuit on bulk ceramic has been done successfully developing a new fabrication recipe for this new substrate [9]. The high dielectric constant of BST reduces the circuit dimensions to tens of microns. We have used a medium resolution $10 \mathrm{kV}$ electron beam lithography machine to pattern the circuit. Poor electrical conductivity of the ferroelectric substrate makes it inappropriate for direct exposure under electron beam, so a $20 \mathrm{~nm}$ metal (Aluminium) layer was evaporated on the substrate. Chemically amplified resist, UV-III, has been used and it has reduced the writing time significantly. Development was carried out using CD-26. The pattern was then transferred to the underlying ferroelectric substrate by evaporating $20 \mathrm{~nm}$ of Chrome and $120 \mathrm{~nm}$ of Gold, followed by a subsequent lifting off.

\section{WIDE-BAND FILTER FREQUENCY RESPONSE AND IM STUDY}

Modelling of the second type of filter was performed using advance electromagnetic simulator ADS-Momentum. Circuits were fabricated successfully on both BST ceramics with $\varepsilon_{\mathrm{r}} \sim 4000$ and with $\varepsilon_{\mathrm{r}} \sim 750$. However, modelling on BST with $\varepsilon_{\mathrm{r}} \sim 4000$ was not very successful due to the high value of permittivity. The measured and simulated frequency responses of the second direct-coupled filter on BST with $\varepsilon_{\mathrm{r}} \sim 750$ are shown in Fig. 10. Here the simulation includes estimates of dielectric loss and conductor losses.

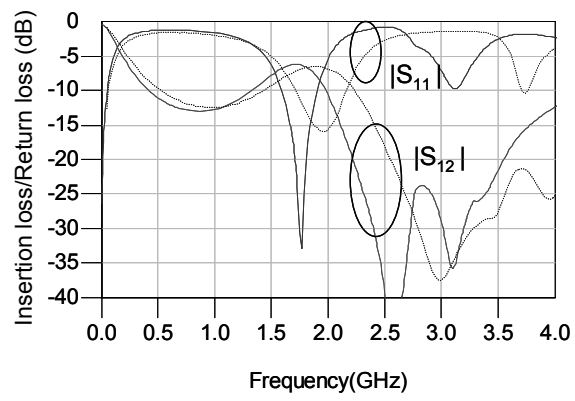

Fig. 10. Bandpass filter frequency response (BST, $\left.\varepsilon_{\mathrm{r}} \sim 750\right)$; solid curves for simulation and dashed curves for measured results.

The measured frequency response shows reasonable agreement with theoretical predictions, particularly in terms of centre frequency, mid-band insertion loss and low frequency response. There is a significant difference between the passband bandwidths of the simulated and measured responses, with the measured $3 \mathrm{~dB}$ bandwidth being $740 \mathrm{MHz}$. This is believed to be associated with the practical test fixture, where spurious couplings between the input and output probes have a significant effect on the location of the finite transmission zero on the high side of the passband. Also the selectivity of the filter is poor on the low frequency side of the passband. This is entirely due to the direct de path from input to output and could be improved by increasing the degree of the filter. Finally the mid-band insertion loss of $6 \mathrm{~dB}$ is a little high for most applications, this is mainly associated with the conductor losses.

For two tone third-order IM measurements of the filter, generation of two relatively pure RF signals at high enough power $(\sim 25 \mathrm{dBm})$ is difficult because of amplifier nonlinearities. The block diagram for IM measurement is shown in Fig. 11. Two tones generated from the signal synthesiser are amplified to equal power levels of $25 \mathrm{dBm}$. These were then passed through two separate transmission channels TX1 and TX2 of a diplexer and were fed into the DUT. The output from 
the DUT was input to a second diplexer to collect the thirdorder IM term in the TX filter, the RX filter was terminated in a high power load. The IM was passed through another narrowband RX filter to remove any unwanted frequencies prior to the spectrum analyser. All the TX and the RX filters in the diplexers are designed very carefully to stop any spurious signals from reaching the spectrum analyser.

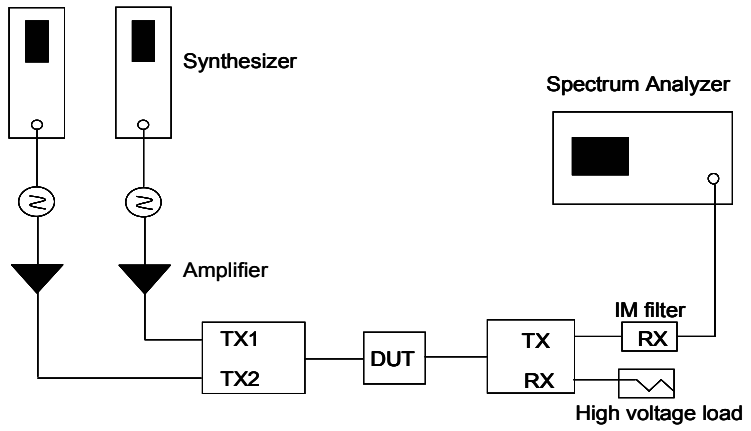

Fig. 11. Block diagram for $3^{\text {rd }}$ order IM measurement of the filter.

The $I P_{3}$ of two tone third-order IM are plotted in Fig. 12. The $I P_{3}$ for tone separations of $46.6 \mathrm{MHz}$ and $33.4 \mathrm{MHz}$ were similar $+74 \mathrm{dBm}$, however as the signal separation was increased to $80 \mathrm{MHz} \mathrm{IP}_{3}$ rises to $+77.5 \mathrm{dBm}$, corresponding output third-order product power level dropped from $-73 \mathrm{dBm}$ to $-80 \mathrm{dBm}$. It is reasonable to conclude from these measurements that the response time of the dielectric (time taken to reach $50 \%$ of its value) was in the region of $10-20 \mathrm{~ns}$.

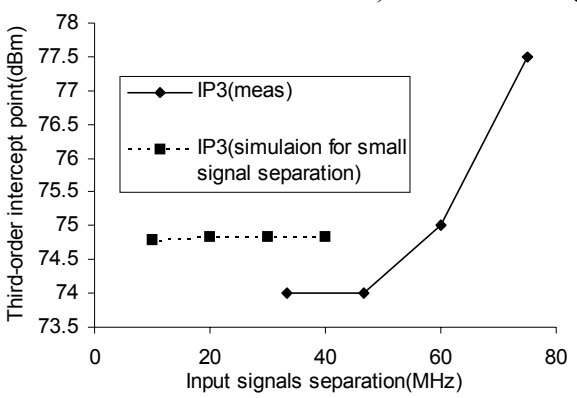

Fig. 12. Third-order intercept point with different separations of the two input tones.

Simulation of the IM performance of the filter has also been carried out using harmonic balance in ADS with a lumped element equivalent circuit model of the integrated filter. The lumped capacitors of the two resonators in the $2^{\text {nd }}$ order bandpass filter were replaced by non-linear capacitor models. The non-linearity of the capacitors was obtained by determining the sensitivity of the centre frequency of the filter to changes in the substrate permittivity using ADS-Momentum. Simulation shows a very similar value of $I P_{3}$ to the measured value with small input signals separations. Note that no attempt was made to include the time-constant of the ferroelectric permittivity in these simulations and hence no comparison of intercept point with measured results at large signal separation has been made. It should also be noted that the intercept point of the wide-band filter is much higher than that for the narrowband combline filter. That is because of passive voltage magnification in the filter resonators, which causes a $6 \mathrm{~dB}$ increase in intercept point each time the filter bandwidth is doubled [10].

\section{CONCLUSION}

Determination of the time constant for some ferroelectric substrates has been done by measuring the third-order IM performance of wideband filters as a function of frequency separation of applied two tone signals. To facilitate these measurements a new type of planar dual-mode ferroelectric filter has been successfully designed and implemented. The filter circuit was successfully micro-fabricated using electron beam lithography and state-of-the-art pattern transfer techniques. The filter frequency response and two tone IM measurements have been presented. The results for output third-order power indicate the material response time to be between 10 and $20 \mathrm{~ns}$. The filter IM performance would thus be better than achievable using semiconductor varactors which respond much faster.

\section{ACKNOWLEDGEMENT}

Thanks to the EPSRC-UK for funding the project and Joint Research Equipment Initiative (JREI) GR/R62021/01 which helped purchasing the EBL machine. The author would like to acknowledge Wai Heng Chow, Paul Steenson, David Iddles, Dave Poppleton and Richard Middleton.

\section{REFERENCES}

[1] I.C. Hunter, J. D. Rhodes, "Electronically tuneable microwave bandpass filters", IEEE Trans., Microwave Theory \& Tech., vol. 30, no. 9, pp. 1354-1360, 1982.

[2] S. R. Chandlar, I. C. Hunter, J. G. Gardiner, "Active varactor tuneable bandpass filters", IEEE Microwave and Guided wave letters, vol. 3, pp. 70-71, 1993.

[3] J. Lin and T. Itoh, "Tunable active bandpass filter using three terminal MESFET varactors," IEEE Microwave Theory \& Tech. Sym. Dig., pp. 921-924, Jun.1992.

[4] I. Vendik etal, "Design of tunable ferroelectric filters with constant fractional bandwidth", IEEE Microwave Theory \& Tech. Sym. Dig., pp. 1461-1464, 2001.

[5] A. B. Kozyrev, "Ferroelectric films at microwaves: Non-linear properties and applications", European Microw. Conf., Munich, 2003.

[6] R. Kurchania, A. J Bell, T. Chakraborty, I. C. Hunter, "An investigation of BST: $\mathrm{MgTiO}_{3}$ and X7R: $\mathrm{MgTiO}_{3}$ based ceramics for microwave applications", IEEE International Ultrasonics, Ferroelectrics and Frequency Control 50th Anniversary Joint Conference, Montreal, Canada, August 2004.

[7] T. Chakraborty, I. C. Hunter, R. Kurchania, A. J. Bell, "Ferrolectric tunable filters for mobile communication", International Conf. for Computers and Devices for Communication (CODEC), India, January 2004.

[8] A. Eriksson etal, "Band-pass filters utilizing dual-mode circular patch resonators", European Microw. Conf., Milan, 2002.

[9] T. Chakraborty, I. C. Hunter, R Kurchania, A J Bell, S. Chakraborty "Novel microfabrication technique for wide-band planar microwave integrated filter on bulk ferroelectric substrates", To be submitted in J. Vac. Sci. Tech.-B.

[10] I. C. Hunter, S. R. Chandlar, "Intermodulation distortion in active microwave filters", IEE Proc.-Microw. Antennas Propag., vol. 145, pp. 7-12, Feb 1998. 